\title{
\#EdTechHub
}

Realising the potential of technology in education

\section{The Maldives and Sri Lanka: Question \& Answer Session}

Taskeen Adam, Tom Kaye, Björn Haßler

EdTech Hub, https://edtechhub.org

Helpdesk Response No. 18

2020-06-18

DOI: $10.5281 /$ zenodo.3885817

For enquiries please email helpdesk@edtechhub.org. 


\section{About this document}

Recommended Taskeen Adam, Tom Kaye, Björn Haßler (2020). The Maldives and Sri Lanka: citation. Question and Answer Session. (EdTech Hub Helpdesk Response No 18)-DOI: 10.5281/zenodo.3885817. Available under Creative Commons Attribution 4.0 International, https://creativecommons.org/licenses/by/4.0/.

Licence. Creative Commons Attribution 4.0 International

https://creativecommons.org/licenses/by/4.0/.

You - dear readers - are free to share (copy and redistribute the material in any medium or format) and adapt (remix, transform, and build upon the material) for any purpose, even commercially. You must give appropriate credit, provide a link to the license, and indicate if changes were made. You may do so in any reasonable manner, but not in any way that suggests the licensor endorses you or your use.

Identifiers. $\quad$ 2405685:HE2Q6Z8Y; 10.5281/zenodo.3885817

Internal use. g/d/1PdYER563FQKojDHdSRBIwphagFg4UVKj-ual iStTOU 


\section{Introduction}

On Tuesday, May 5, 2020, the EdTech Hub participated in a question and answer session for policy-makers and tertiary education stakeholders in The Maldives and Sri Lanka. The session focused on the challenges and issues in designing high-quality, effective, distance education programmes during the COVID-19 pandemic. Participants included high-level officials from the Maldivian and Sri Lankan governments (e.g., the Ministry of Education and the Ministry of Communication, Science and Technology), representatives from development partners (e.g., the World Bank) and various stakeholders in the tertiary education sector (e.g., universities and TVET colleges). Representatives of certain states of India, namely, Uttar Pradesh, Andhra Pradesh and Jharkhand were also in attendance.

The session was convened for two purposes. First, to consider international good practice and current trends in distance education during the COVID-19 pandemic, presented by the World Bank EduTech team and the EdTech Hub. Second, for the EdTech Hub team to gather questions from participants, to be able to target guidance specifically to the situations in The Maldives and Sri Lanka.

This document provides answers to a consolidated list of 13 questions received from stakeholders before and during the session. To consolidate any overlap, we have occasionally combined multiple questions into one. In other cases, where multiple important issues required a focused response, we split apart questions. This document outlines the following two sets of questions.

\section{Set 1. Questions from The Maldives}

- Question 1: What are the most cost-effective technology options for higher education and where are they used currently?

- Question 2: One of the biggest challenges in using education technologies and online resources is the cost of internet access in The Maldives. What strategies and technologies do you propose to overcome such access issues?

- Question 3: How can we transition from traditional teaching to technology-enabled teaching in higher education?

- Question 4: The Maldives higher education sector is a young sector. What are effective practices for introducing new technologies into a developing young sector?

- Question 5: We have all the basic building blocks needed (e.g., teleclasses, training, data providers, parents, devices), but how do we bring these together to support learning?

- Question 6: What digital literacy skills need to be developed in basic education to ensure that students graduating into higher education are equipped with the right skills for technology-enabled and technology-driven higher education?

- Question 7: How can we assess and ensure that students are learning at home?

- Question 8: How can a home-based early childhood development programme be developed and supported? 


\section{Set 2. Questions from Sri Lanka}

- Question 9. There is anecdotal evidence of frustration among parents / caregivers resulting from an inundation of technology and online learning materials (which parents have to learn first, before they can teach children). Is there any current thinking on how to help parents navigate these issues?

- Question 10. Is there an evolving database of e-learning tools that can be used in low-resource settings? If so, is there further information on where these tools are being used and how effective they have been?

- Question 11. In the TVET sector in Sri Lanka, providing digital skills for trainees who follow non-ICT technical courses will be a big challenge when introducing distance learning. What strategies can be applied to enhance the digital skills of the trainees in non-ICT courses? Furthermore, as many TVET courses require practical training, how can this be shifted to distance learning?

- Question 12. Content development is one of the main processes in the distance learning flow. What are the latest convenient tools for content development?

- Question 13: How effective is the use of virtual reality or augmented reality in improving learning outcomes?

The above questions are also relevant to audiences beyond The Maldives and Sri Lanka. They are generally representative of questions we receive from similar groups around the world. Therefore, this document has been made publicly available to provide insights to policy-makers, programme funders, private sector actors, and other stakeholders working on EdTech.

See Appendix A for a list of other relevant resources developed by the EdTech Hub. 


\section{Questions from The Maldives}

\section{Question 1: What are the most cost-effective technology options for higher education and where are they used currently?}

When considering cost-effectiveness, one needs to consider both the development and implementation costs by the institution, and the usage costs for the students. The most cost-effective technology options for higher education, from the development and implementation side, are those that:

- reuse and adapt existing Open Educational Resources available;

- use existing tools, software and learning platforms;

- leverage existing devices and infrastructure instead of mass purchasing devices or building new infrastructure.

From the usage side, cost-effective options are those that:

- do not require learners to have expensive devices;

- do not require large amounts of data to access content.

Any strategies to mitigate the COVID-19 crisis should be designed in a way that maximises the effectiveness, efficiency and equity of services provided. Institutions should develop responses that leverage multiple modalities aligned with the national context (e.g., socio-economic factors, national demographics, infrastructure, state of the national education system).

Countries and their educational institutions should also take stock of and, where possible, leverage existing ICT infrastructure. It is, however, impossible to significantly increase infrastructure in the timescales that are required for an immediate response. Countries should therefore refrain from attempting to build new infrastructure to specifically respond to the COVID-19 crisis. Expanding infrastructure should happen as part of clear plans to create resilience against the kinds of challenges raised by the COVID-19 crisis. For any infrastructure built, continued relevant use should be considered.

\section{Modalities to support distance education}

Across the many and diverse contexts globally, seven types of modalities are most commonly being used to support distance learning. These are illustrated in Table 1. 
Table 1. Distance learning modalities and technologies (Source: Adapted from Delivering Distance Education in Emergencies (iUSAID, 2020) $)^{1}$

\begin{tabular}{|c|c|c|}
\hline Modality & Technology & Educational use \\
\hline Print media & $\begin{array}{ll}\text { - } & \text { Books } \\
\text { - } & \text { Pamphlets } \\
\text { - } & \text { Magazines } \\
\text { - Newspapers }\end{array}$ & $\begin{array}{l}\text { - } \quad \text { Printed teaching and learning material e.g., } \\
\text { textbooks and workbooks } \\
\text { - Newspaper articles }\end{array}$ \\
\hline Audio & $\begin{array}{ll}\text { - } & \text { Radio broadcasting } \\
\text { - } & \text { MP3 and MP4 players } \\
\text { - } & \text { Feature phones } \\
\text { - } & \text { Smartphones/Tablets } \\
\text { - } & \text { Laptops/Computers }\end{array}$ & $\begin{array}{l}\text { - Interactive audio / radio instruction } \\
\text { - } \quad \text { Audiobooks, podcasts, radio dramas, } \\
\text { two-way programmes }\end{array}$ \\
\hline Broadcast Video & $\begin{array}{l}\text { - } \quad \text { TV broadcasting } \\
\text { - } \quad \text { Smartphones / Tablets }\end{array}$ & $\begin{array}{l}\text { - } \quad \text { Video instruction programming } \\
\text { - } \quad \text { Educational television broadcasting }\end{array}$ \\
\hline $\begin{array}{l}\text { SMS and phone } \\
\text { calls }\end{array}$ & $\begin{array}{ll}\text { - } & \text { Feature phones (not } \\
\text { internet-enabled) } \\
\text { - } \quad \text { Feature phones (internet } \\
\text { enabled) } \\
\text { - Smartphones }\end{array}$ & $\begin{array}{l}\text { - } \quad \text { Broadcast messaging on important } \\
\text { - } \quad \text { Calling parents and learners }\end{array}$ \\
\hline $\begin{array}{l}\text { Web-enabled } \\
\text { mobile learning }\end{array}$ & 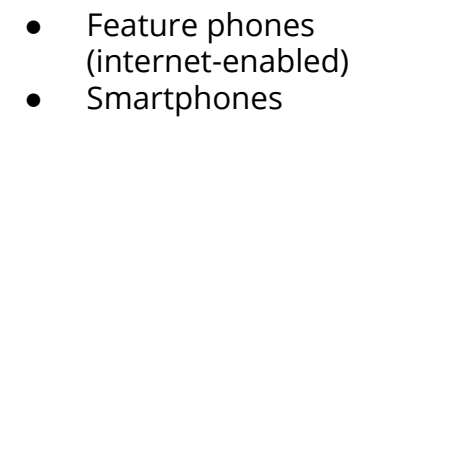 & $\begin{array}{l}\text { - Electronic teaching and learning materials } \\
\text { (e.g., learning packs, M-novels, mobile } \\
\text { storybooks) } \\
\text { - Use of Open Educational Resources } \\
\text { - Virtual web-based teaching and learning } \\
\text { groups } \\
\text { Web-based mobile-compatible Virtual } \\
\text { Learning Environments and Massive Open } \\
\text { Online Courses (MOOCs) } \\
\text { Web-based communication platforms / } \\
\text { instant messaging (e.g., email or Facebook } \\
\text { Messenger) }\end{array}$ \\
\hline $\begin{array}{l}\text { Application- } \\
\text { based mobile } \\
\text { learning }\end{array}$ & $\begin{array}{l}\text { - } \quad \text { Smartphones } \\
\text { - Tablets }\end{array}$ & $\begin{array}{l}\text { - } \quad \text { As above } \\
\text { - } \quad \text { Virtuational apps and games } \\
\text { groups } \\
\text { - App-based Virtual Learning Environments } \\
\text { and MOOCs } \\
\text { - App-based communication platforms / } \\
\text { instant messaging (e.g., WhatsApp) }\end{array}$ \\
\hline $\begin{array}{l}\text { Web-enabled } \\
\text { laptop learning }\end{array}$ & - Laptop/Desktop & $\begin{array}{l}\text { - } \quad \text { Same as 'web-enabled mobile learning' } \\
\text { - } \quad \text { Folly functional Virtual Learning } \\
\text { Environments } \\
\text { - } \quad \text { Synchronous teaching through } \\
\text { - } \quad \text { video-conferencing tools } \\
\text { ScreenCasting }\end{array}$ \\
\hline
\end{tabular}

\footnotetext{
${ }^{1}$ The USAID report used four categories: radio / audio, TV / video, mobile phone and online learning. These categories were expanded by the authors to the seven categories displayed in Table 1.
} 
These modalities are most powerful when deployed in an integrated, multi-modal strategy designed to meet the needs of all learners. In terms of basic education, broadcasting through radio and TV works well. For example, children might watch educational content on TV and then interact with SMS quizzes. The responses to these quizzes allow teachers to see whether the children have understood the content.

\section{Cost-efficient options for higher education}

In higher education, print media, mobile phones and laptops are more applicable than radio and TV. This is because content is specific to the courses being taken and cannot be delivered through broadcasting. Higher education is thus more dependent on digital means than basic education. As not all higher education learners have access to a laptop - even in high-income countries - mobile phones are a more cost-efficient type of technology to design higher education e-learning around. Additionally, learners may be more digitally literate with mobile phones than laptops. While they may be more cost-efficient, they may not always be the most cost-effective as small screen sizes can inhibit quality learning. In terms of cost-effectiveness, tablets could provide a more optimal point between cost and quality of learning. Using these technologies, teaching and learning in higher education can continue through the use of:

- correspondence communication through posting / collecting learning material;

- SMS and phone calls on non-smartphones;

- web-based communication and learning on non-smartphones

- Virtual Learning Environments ${ }^{2}$ that are populated with existing Open

Educational Resources that can be tailored and adapted.

- 'Wrapping' of MOOCs with learner support and contextualisation;

- messaging and learning apps on smartphones;

- online learning on laptops.

The technologies and the educational opportunities they provide are outlined below.

\section{Correspondence through print-media}

Learning through correspondence, where printed material is posted via mail to the learner, has been a form of distance education in higher education for decades (iBozkurt, 2019). In cases where posting is not possible, learning material can be collected from the educational institute or from a designated location in a community. This form of education was designed specifically to include learners that were not able to attend university in person (ibid.).

In the race to use technology to support online learning, print materials are often forgotten. However, they are generally the most accessible and equitable option to support distance learning - both in terms of access by learners who do not have access to devices and / or connectivity at home, and in terms of government / institutional readiness to distribute materials.

\footnotetext{
${ }^{2}$ The use of the term 'Virtual Learning Environments' in this report has the same meaning as 'Learning Management Systems'.
} 
Printed materials may come in a number of forms. These materials might include textbooks, supplementary reading material, exercises and assessments. Any printed materials should include guidance to support learners to integrate them with any other available tools or modalities.

\section{SMS and phone calls on non-smart phones}

Non-smartphone features can be split into two groups: those that do not need the internet (e.g., SMS and calling), and those that do (e.g., web-browsing and web-based messaging). SMS and phone calls can be used to support communication about education generally. This can be to provide updates, check up on learners' wellbeing or send tasks and reminders. SMS can be used as a mechanism to administer behavioural nudges to encourage learners in their learning activities. Bulk SMSs can also be used to inform learners of important messages, e.g., up-to-date information on lockdown limitations and institutional decisions.

\section{Web-based communication and learning on non-smartphones}

If phones have internet capability and learners have intermittent connectivity, emails can also be used to communicate with learners. Web-based messaging (e.g., Facebook Messenger) can also be used on some non-smartphones, where groups can be set up to support learners and create a space for them to support each other.

Although many non-smartphones cannot download apps, websites or Virtual Learning Environments that are low on data can be used to share reading material, podcasts and short videos. Virtual Learning Environments allow educators to select and curate content for a specific course. It is important that these websites / platforms:

- are backward-compatible for usage on older phone models and older browsers;

- are mobile-compatible to various mobile screen sizes;

- use low bandwidth.

Getting these websites zero-rated would remove the barrier of data costs that many learners face (See Question 2).

Content for Virtual Learning Environments can be obtained and adapted from a variety of Open Educational Resources available for higher education. Open Educational Resources are openly licensed content that are retainable, revisable, remixable, reusable and redistributable. The Mason OER Metafinder is a useful aggregator that searches through various Open Educational Resource repositories. A list of OER repositories for tertiary education can be found in Appendix $B$.

MOOC platforms ( i.e., platforms with curated content packaged into free online courses) such as FutureLearn have been designed to be backward compatible and are thus usable on feature phones. This provides an opportunity for educators to use these MOOCs in a 'wrapped' function. This is, when content from a MOOC is re-used with a dedicated educator, a learner support structure, and a smaller number of learners (^Deacon, et al., 2018). By wrapping MOOCs, educators leverage existing curated content while additionally adding further supplementary material and learning support to better contextualise and guide the learning experience. $\underline{\text { P2PU }}$ offers a similar function 
where learning circles can be created for participants to do online courses together, either online or in person.

\section{Messaging and learning apps on smartphones}

Smartphones allow learners to access a broader range of digital learning tools wherever connectivity is available. Smartphones open up a wide variety of learning opportunities that traverse both the features outlined in non-smartphones above, as well as those accessible on laptops and other large-screen devices outlined in the following sub-section.

In addition to replicating access to content found on these tools, smartphones also host a wide array of applications that can support high-quality distance learning:

- Messaging apps such as WhatsApp, Messenger, Telegram or Moya;

- MOOC apps such as the Coursera and edX;

- Virtual Learning Environment mobile application such as Moodle.

A key feature to look for when choosing a mobile learning platform is whether it can be used offline and synced when there is internet connectivity, such as in the case of the Coursera and Moodle applications.

While MOOC platforms and Virtual Learning Environments offer discussion forums, learners often still prefer to chat on messaging applications such as WhatsApp as they are more familiar to learners, user-friendly and low on data (^Adam, 2020). Tasks, multiple-choice questions, quizzes and assessments can take place on the mobile platform, however, functionality is limited. It is hard to complete long writing tasks on a mobile application.

While Virtual Learning Environments and MOOC platforms offer opportunities for asynchronous learning (i.e., teaching and learning where the educator and learner do not need to be online / available at the same time), conferencing applications such as Zoom, Webex, Microsoft teams and many others, allow for lessons to take place synchronously (i.e., when the educator and learner communicate in real-time online). Synchronous learning is not feasible for the marginalised in low- and middle-income settings as it has high data costs and requires everyone to have access to a device and good-quality connectivity at the same time. If this mode of teaching / learning is used, caution should be taken to not simply present a lecture, but use the time to interact and engage with the learners, e.g., using a flipped classroom method where content is covered before class and the synchronous online time is used to discuss and unpack the topic. Lecture-style education does not work for children generally, but may be more appropriate for adult education. Synchronous online learning requires additional and more engaging pedagogical approaches to be successful. ${ }^{3}$

\footnotetext{
${ }^{3}$ Regarding general video conferencing, we also note that some applications are more bandwidth aware than others. For example, https://meet.jit.si is the only video-conferencing application we know off that shows user-bandwidth during calls. Additionally, it allows user-side bandwidth management; users are able to set the video quality (or, indeed, turn off video completely).
} 


\section{Online learning on laptops}

Laptops include all the previous modes of learning provided by phones, but offer a better user experience due to a larger screen size. For example, digital learning material such as e-books can be read more comfortably on a laptop screen. While online courses can be done through mobile phones, assignments that need typing are better done through a laptop. Additionally, laptops are more essential for computer science learners who need to practice programming. Often, MOOC platforms, Virtual Learning Environments and web-conferencing platforms have better user interfaces with more features when used on a laptop. Online versions often consume more data than the mobile applications, resulting in higher user costs.

\section{Question 2: One of the biggest challenges in using education technologies and online resources is the cost of internet access in The Maldives. What strategies and technologies do you propose to overcome such access issues?}

Three strategies are highlighted to overcome high internet costs as a barrier to access.

\section{Design lean websites and content}

Keep websites and Virtual Learning Environments free from unnecessary graphics and designs. Additionally, design or use content that is not data intensive, e.g., use text, graphics and audio where possible and keep video to a minimum.

\section{Work with telecommunications providers to zero-rate educational websites and applications}

In many countries, higher education institutions are working with telecommunications providers to zero-rate content. Zero-rating allows internet users to access certain websites and use certain applications without incurring data charges. We have written a brief on zero-rating educational content in low- and middle-income countries to unpack the zero-rating process more clearly. Before zero-rating is considered as an option, it should be ensured that learners have access to adequate network infrastructure and devices to take advantage of zero-rating. Additionally, websites need to be designed for zero-rating. Technologically, it needs to be low on data, use minimal bandwidth and be mobile compatible. Pedagogically, it needs to be user-friendly for learners with low digital literacy and offer learner support to those new to online, self-directed learning.

Mobile applications can also be zero-rated. For example, Moya Messenger provides data-free messaging services in Nigeria and South Africa. This type of platform can facilitate improved teacher-learner and teacher-parent communication during the current pandemic.

\section{Make use of offline repositories}

Educational platforms exist that only require limited data usage. Kolibri, for instance, offers an open repository of curricular-aligned content and exploratory learning materials that users can access in low-resource settings (e.g., rural schools, refugee camps, orphanages, prison systems). It allows users to access downloaded resources 
offline and share content with other learners via local networks. In particular, the platform hosts subject-specific videos, reading materials, simulations, games, lesson plans and pedagogical guides. This will provide a one-stop shop where teaching and learning material are available for everyone.

\section{Question 3: How can we transition from traditional teaching to technology-enabled teaching in higher education?}

Before investigating how to transition from traditional teaching to technology-enabled teaching, educational institutions need to determine whether such a transition is needed and is feasible. For instance, TVET colleges that specialise in practical, hands-on training need to continue with in-person learning (See Question 11). Teachers' and learners' accessibility need to be considered to assess their readiness. This guides the type of technology-enabled approaches that can be used. Table 2 outlines questions to investigate accessibility.

\section{Table 2. Accessibility concerns}

\begin{tabular}{|l|l|}
\hline \multirow{4}{*}{$\begin{array}{l}\text { Accessibility } \\
\text { concerns }\end{array}$} & $\begin{array}{l}\text { Do teachers and learners have access to appropriate hardware } \\
\text { (e.g., feature phone, smartphone, tablet)? }\end{array}$ \\
\cline { 2 - 2 } & $\begin{array}{l}\text { Do teachers and learners have access to phones with sufficient } \\
\text { storage capacity and features to support mobile applications? }\end{array}$ \\
\cline { 2 - 2 } & Does access to hardware vary across regions? \\
\cline { 2 - 2 } & In which regions do service providers offer internet coverage? \\
\hline & $\begin{array}{l}\text { How does internet coverage and bandwidth strength vary across } \\
\text { regions? }\end{array}$ \\
\cline { 2 - 2 } & To what extent are teachers and learners digitally literate? \\
\hline
\end{tabular}

Before guiding on technology-enabled teaching, it is important to note the difference between planned online and distance education and emergency remote education (iBozkurt, et al., 2020). The former is long-term and designed appropriately for its purpose and typically has trained instructional designers supporting the process (ibid.). Emergency remote teaching on the other hand (i.e., what educators may be doing during the pandemic) is an immediate, ameliorative response to a situation that was never planned for. Further, the educators are unlikely to be trained in digital pedagogies and digital content development (ibid.). The emergency support strategies needed to make it through the pandemic are different to the more long-term professional development strategies needed in the transition to technology-enabled teaching.

While responding to emergency needs, interventions that will help build long-term capacity for distance education should be prioritised. According to the World Bank, the pandemic is expected to minimise increases in education spending in 2020. Additionally, spending will likely plateau or fall in 2021. Given the likelihood of these reductions, any 
resources used in the immediate response can be evaluated with cost-effectiveness and relevance to long-term impact in mind.

Regarding emergency remote education, expectations for educators need to be realistic and feasible in light of the situation. This is outlined in the overview of emerging country level response to providing educational continuity under COVID-19. It is important to note that educators who have never worked in an online environment, nor used any remote learning tools, need time to get used to these new tools. They cannot become instructional designers overnight as that is in itself a different job. They may also feel anxious as they tread through uncharted waters during the crisis. Unrealistic expectations and inadequate guidance may impact educators' motivation and lead to frustration, which, in turn, affects their learners. Just as learners need an increased amount of care and support from their educators, educators also need an increased amount of care and support from their institutions. Institutions should provide guidance and support to educators and set clear expectations. Guidance should include what educators should do, should not do, and how they can do it. In the short term, some online courses have been launched during the COVID-19 crisis to support educators in creating content and pivoting to online teaching. Additionally, online resources to support remote teaching, particularly with low-tech solutions, have also been made available.

In terms of supporting educators, peer networks of teachers are an important way to discuss issues of practice ( Kelly \& Antonio, 2016). Communities of practice can utilise messaging platforms such as WhatsApp, Skype, Telegram and others. Making such educator peer groups effective includes considerations such as the number of members needed in order to have critical mass, or having a senior, experienced educator who is comfortable with remote teaching as a default go-to person.

Crucially, learners need to be supported in the shift to online or remote learning, particularly if they have never experienced it before or have not developed self-directed learning capabilities. There are a number of things educators can do to support learners during the COVID-19 crisis. First, even in the current crisis, educators can structure the teaching and learning of their learners. Learners need to know the focus of the teaching sessions and how to engage with the topics. Educators simply checking in with learners can motivate learners and give them a sense of stability and routine. Second, educators should - as usual — adapt their teaching approach to learner needs. Struggling learners may need extra support. Third, educators might be able to assess to what extent learning is taking place. If teachers manage to check in with learners via message or email, they can also discuss the results of practice exercises.

During this time, it is unrealistic to expect educators to create new educational content from scratch, or for teaching and learning to 'continue as normal'. During the COVID-19 pandemic, the Commonwealth of Learning has led an initiative where over 44 educational institutions are openly sharing their content and courses online. The availability of such Open Educational Resources and MOOCs provides ample room for content reuse and adaptation before educators resort to creating their own new digital content. 
Looking at the longer term, the following considerations need to be taken into account when planning to transition from traditional teaching to technology-enabled teaching:

- Both educators and learners need to be supported in the transition to technology-enabled teaching and learning.

- Strong guidance and professional development needs to be given by institutions to support educators transitioning to technology-enabled teaching.

- Edtech-enabled professional development needs to be conducted with educators over a sustained period of time, where they can put into practice what has been learnt - one-off workshops do not work.

- The transition needs to be gradual and expectations of educators need to be managed.

- An adaptive edtech-integration strategy needs to be developed (See Question 4 and Question 5).

When transitioning to technology-enabled teaching it is important to remember that educators are still the bedrock of the system. Educators provide structure to learners, adapt to the different situations and needs of the learners, and assess whether learning takes place. The ability for educational technology to enhance the learning experience is only as good as the educator utilising it. Educators are an essential part of the education system, and they remain essential in online and distance learning. This needs to be made known as some educators fear that their jobs will be replaced by technology and thus resist it.

\section{Question 4: The Maldives Higher Education sector is a young sector. What are effective practices for introducing new technologies into a developing young sector?}

When developing an edtech-integration strategy, there is often an impulse to invest in mass purchasing of devices. However, this is not the optimal point for investment and, if anything, should be the last step in the edtech-integration strategy. The following approaches are recommended:

1. Clearly unpack the problem that needs to be solved. A common problem in development is that a problem is often defined as lack of a preferred solution. A shift is needed from a solution-driven approach to a problem-driven approach. The Problem Driven Iterative Adaptation is an approach designed for governments that is extremely useful in unpacking complex problems (see further details below).

2. Engage with the ministries of education and decision-makers in higher education to make them fully aware of the opportunities and limitations of educational technologies. It is important to not envisage edtech as a silver bullet but understand that it is one part of a complex education ecosystem.

3. View the creation of an edtech-integration strategy as an iterative, adaptive process rather than a static 10-year implementation plan. Technology is fast evolving and so are the needs and contexts of educators and 
learners. An adaptive approach allows for quick maneuvering when sudden curve balls hit, e.g., The COVID-19 pandemic.

4. Design a strategy that is appropriate for the country's contexts, The strategy depends on the availability of devices to the population and the infrastructural readiness of the country. Trying to replicate edtech approaches used in other countries, e.g., countries with more infrastructure, will lead to wasted investment into developments that will go unused. Lessons from regional and international experiences can, however, be drawn upon to better inform local strategies.

5. Focus on developing human capacity through professional development programmes that incorporate digital pedagogies. Before investing in technology, investment is first needed in building the capacity of educators to use, manage and maintain the new system. Capacity cannot be built overnight and a gradual approach is needed. Instead of one-off workshops, educators need to slowly experiment with new technologies in their teaching.

\section{Use agile practices to support the development of an edtech-integration} strategy. Agile approaches are iterative, flexible and adaptable and prevent mass investment in untested strategies too early on. (See Question 5).

Before jumping into a particular solution, we highly encourage using the Problem-Driven Iterative Adaptation toolkit to fully understand the problems that need to be addressed. The toolkit is a step-by-step approach which helps to break down problems into its root causes, identify entry points, search for possible solutions, take action, reflect upon what has been learnt, adapt and then act again. It is a dynamic process with tight feedback loops that allows you to build your own solution to your problem that fits your local context. Problem-Driven Iterative Adaptation is a learning-by-doing approach. The toolkit outlines eight steps which each introduce a new concept along with tools to support the process:

1. Constructing the problem;

2. Deconstructing the problem;

3. Sequencing: Using change-space analysis to find entry points;

4. Crawling the design space for possible solutions;

5. Building and maintaining authorisation;

6. Designing the first iteration;

7. Learning from the iterations;

8. Moving onwards.

In addition to being a dynamic process with tight feedback loops that allows you to build your own solution to your problem, Problem-Driven Iterative Adaptation strongly emphasises local solutions to local problems. 
Question 5: We have all the basic building blocks needed (e.g., teleclasses, training, data providers, parents, devices), but how do we bring these together to support learning?

Agile approaches shift thinking from the understanding of 'building blocks' to the understanding of 'iterative development', where approaches can be tested at a small scale, before developing a strategy further. Figure 1 illustrates this well.

Figure 1. Agile development vs traditional development approaches

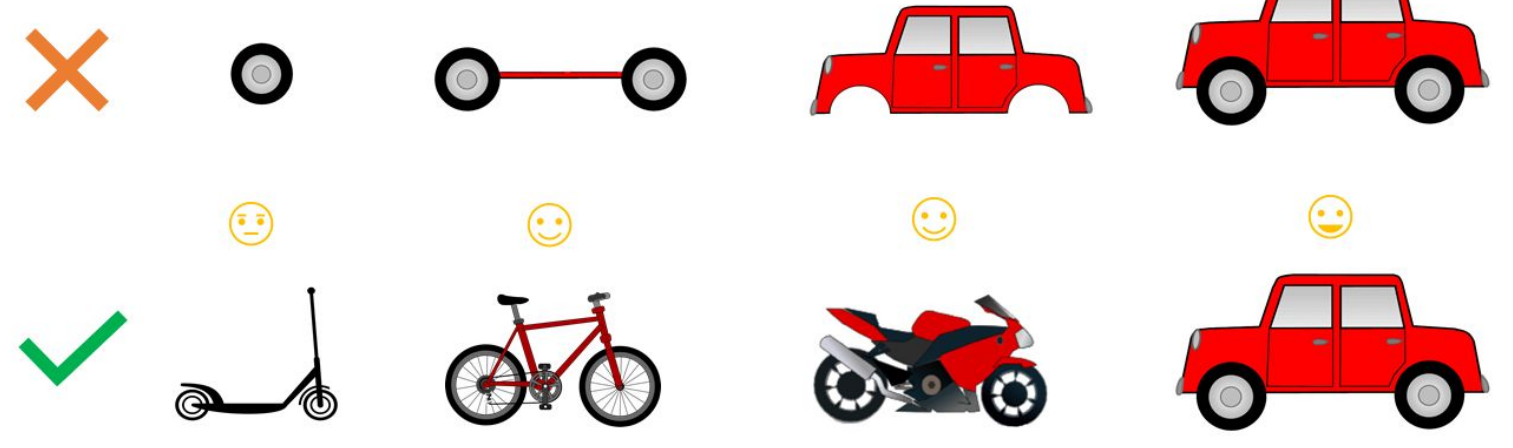

The UK Government Digital Service has outlined four phases in their agile approach.

1. Discovery. The discovery phase, where the problem is fully investigated. This investigates the different users and their contexts, the constraints, and the possible opportunities. Problem-Driven Iterative Adaptation overlaps with this phase and can be integrated here.

2. Alpha. The alpha phase is where multiple small prototypes of solutions are designed and implemented which aim to address the problem.

3. Beta. The beta phase is where the best idea from the alpha phase is developed further and tested at a larger scale.

4. Live. The live phase is when the solution is supported in a sustainable way at full scale, while continuing to iteratively improve it.

Between every phase, it is important to reflect and review what has worked and what has not, before moving onto the next phase. This type of approach is collaborative and allows for the views, needs, limitations and requirements of various stakeholders to be incorporated at various points. This leads to an alignment of actors which is crucial to the success of an intervention.

To apply this approach to the implementation of an e-learning strategy, each user's role and journey in the e-learning system should be unpacked, i.e., the learners, the parents, the educators and the educational institution. For example, whether educators are ready and comfortable to use new technologies is a crucial point to be investigated as educators are pivotal to the success of the e-learning strategy. The strategy thus needs to investigate how educators can be better supported. Beyond professional development, they may need socio-emotional support and more care and guidance 
from the institution. This can only be unpacked by working closely with them and incorporating their needs into the approach.

\section{Question 6: What digital literacy skills need to be developed in basic education to ensure that students graduating into higher education are equipped with the right skills for technology-enabled and technology-driven higher education?}

At a basic level, learners need to learn how to use a mouse and keyboard. Learning these skills can often be done in fun and creative ways such as through games like Minecraft for Education. Learners need to be familiar with common user interface features such as buttons, dropdown menus and hyperlinks. The use of word documents and spreadsheets is also important.

Beyond basic digital literacy, learners need to develop internet literacy skills such as how to search, use multiple tabs, and filter out advertising and hoaxes from relevant, reliable information. This leads to the need to develop critical digital literacy skills to help learners safeguard themselves against fake news and misleading information. With access to the internet, the problem is no longer lack of information, but a lack of quality, curated content to guide learning. Thus, a key skill that needs to be developed among learners is being able to guide their own learning experience through the chaos of information available.

Learners also need to be made aware of how to protect themselves online, e.g., how to engage with strangers. As they spend more time online, their digital footprints increase and websites may be collecting data on their movements; learners also need to be made aware of this and know what they are consenting to when they use certain websites. UNESCO has released a guide on personal data security for online learning platforms.

When introducing technology in basic education, it should not only be taught as a separate subject but used to support subject learning as well, such as GeoGebra which supports learning maths, or Marble which supports learning geography. Finding such software need not be an expensive endeavour as there is a lot of open-source learning software that can be used to support learning.

Teaching learners basic coding and hardware-software integration can also go a long way in supporting learners to gain an in-depth understanding of digital technology, and being familiar and comfortable with it. For example, Raspberry Pi or Microbit offer fun ways to teach learners the basics of robotics. To support better understanding of coding, mathematics and language skills are particularly important as coding requires critical thinking and problem-solving skills.

\section{Question 7: How can we assess and ensure that students are learning at home?}

There are two main types of assessment: formative and summative assessment. Their purposes are different, as are the ways they can be implemented. During the crisis, formative assessment is particularly important because educators and parents need to gauge whether learners have been able to learn in the new formats that are being used. 
Formative assessment aims to identify learners' current competency levels and gaps in their learning and whether learners need remedial support. By definition, a learner cannot fail a formative assessment, and a formative assessment should not be used to judge a learner. A summative assessment is an official 'test': it measures whether a learner has learnt what they are supposed to have learnt. If they pass, they move forward to the next skill, subject or year. If they fail, they have to do the skill, subject or year again. These two assessment types require different implementation approaches.

Formative assessment gives teachers the most freedom to experiment and allows for many formats. In distance learning, knowledge checks can be performed through SMS, individual or conference calls, or with a plethora of online tools. In Pakistan, for example, an SMS Edu Portal that enables bitesize content over SMS has been integrated with broadcasted educational TV lessons. The advantage of formative or ongoing assessment is that educators can correct misunderstandings as they arise, while learners are still engaging with the content. Apart from getting feedback from their own teachers, learners might access "Homework Hotlines" to receive feedback on study questions and exercises.

Countries take different approaches to summative assessment. Some countries, like Austria, have suspended formal assessments until school restarts. Other countries have adjusted or are adjusting their laws to allow for remote assessment. Some universities are offering pass or fail options instead of graded results. There are countries that work with the technology they have, such as mailing or emailing material to schools or teachers. Finally, some countries base their learner assessment on the work and assessments learners have done in class.

No solution is perfect, and each has advantages and pitfalls. Not having assessments may mean that all learners pass, risking devaluing their diplomas in the eyes of future employers. Having assessments in an unsupervised setting risks plagiarism and fraud. Basing a final assessment on formative assessments risks turning formative assessments into summative assessments, which threatens the learning effect and objective of a formative test.

\section{Question 8: How can a home-based, early childhood development programme be developed and supported?}

Mass Early Childhood Development programmes can be rolled out through television and radio shows. Educational TV programming can be highly engaging for students and can include cartoons, animations, science shows and history documentaries. Educational television programmes, such as Akili and Me, Sesame Street, Know Zone and Ubongo kids, have been shown to have had positive effects among pre-primary learners. Similarly, interactive radio instruction has the potential to reach children in remote areas. A curated list of Interactive Radio Instruction used to support educational needs during the COVID-19 pandemic can be found here. Both TV and radio content can be made available online through videos / podcasts enhancing education accessibility and equity.

It is possible to support learning at an early childhood development level (i.e., children between the ages of 0-5) at home with little access to technology. At this level, parents play a crucial role in the development of their children, irrespective of the current 
pandemic. The support for learning at home guideline for caregivers offers great advice on how to do this with little access to resources. Caregivers need not be highly educated to support their children; they just need to be motivated.

Before engaging with their children, caregivers need to first manage their own anxiety and stress to ensure it is not passed onto their children. In this time, it is possible for caregivers to be more angry or upset than usual and it is important not to take this out on one's children. caregivers need to be attentive, listen to their children and answer any questions they may have, and use positive language.

Caregivers can set aside a timeslot in the day to spend with their children, even if it is only 20 minutes. Doing this routinely at the same time and in the same spot in the house adds a sense of stability and gives them something to look forward to. In this space, caregivers can put toys or safe items that can be played within reach of the child. Books can also be placed around, even if caregivers cannot read, as it will familiarise the child with the concept of reading.

In terms of activities, caregivers and children can sing songs or rhymes, do puzzles or play games together. Simple games like hide-and-seek or I-spy can be played. Activities can also involve movement like dances or moving around the home. When parents cannot take time off for their children, activities embedded in daily routines can be highly effective. Chores like cooking, cleaning or gardening can be turned into fun games where concepts or numeracy can be learnt. For example, they can learn to count, match, compare or follow a set of instructions. Activities should try to draw on different senses such as smell, touch, sight.

Creating a story time, where stories are read or told is a great way for the family to spend time together (including older children). For parents that cannot read, books with illustrations can be used and the parent can generate their own creative stories. Song and dance can also be incorporated into approaches. Encouraging questioning and reflection is a useful technique to prompt critical thinking. There are many openly licensed story books available, such as African storybooks, which can be printed and distributed to caregivers.

\section{Questions from Sri Lanka}

\section{Question 9. There is anecdotal evidence of frustration among parents / caregivers resulting from an inundation of technology and online learning materials (which parents have to learn first, before they can teach children). Is there any current thinking on how to help parents navigate these issues?}

While it is more feasible for parents to support young children (e.g., 0-5-years old) at home, as this is often the case for this age group, the job becomes harder for children in primary and secondary education who need more specialised educational support. Lessons from the Ebola crisis show that there was limited benefit to providing self-study materials for use without the support of a caregiver ( $\$$ Plan International, 2016). Parental attitudes towards education can significantly influence the extent to which children engage with available resources. Caregivers and parents are not teachers, and should 
not be treated as such. Additionally, parents are dealing with high levels of stress during this time, e.g., they may be having difficulty finding employment or battling with self-isolation. It is thus important for governments and educational institutions to not place too much burden on parents during this time.

As with young children, parents and caregivers can help their children develop academic and other skills as part of daily routines. These activities can also provide great contextualised learning and can be more engaging to both parent and child than formal schoolwork. For these activities, a parent's imagination is the limit! For maths, parents can engage with a child of any age group. In the shop, younger children can count coins while older children can calculate change or make a budget for shopping. Activities supporting literacy can range from identifying letters on signage or household items, to reading a recipe and making the dish, to keeping a diary. Schools may also provide specific instructions or activities for parents to support literacy. Categorising types of rubbish outside, discussing ways of disposing of them, and composting kitchen materials can all be part of science activities. At home, parents can support learning across multiple 'subjects'. For example, a combined activity may include creating a budget for ingredients needed for a dish, buying them, understanding how yeast works, cooking a dish, and disposing of food waste responsibly. The possibilities are endless.

To support parents, educational institutions need to provide practical suggestions on activities that parents can integrate into their daily routines without much cost. Educational institutions should send caregivers messages with encouragement and actionable suggestions on how they can support home-based learning. Recent evidence from J-PAL suggests that the most effective strategy involves sending parents three text messages each week. These messages should recommend activities that reflect a student's academic skill level. Bridge International Academies offer a good example of how an organisation can support caregivers through a scaffolded approach.

In cases where schools are providing remote learning through technology, parents are required to assist in supporting learners with their remote learning at home. It is important for schools to communicate clearly with parents and give them clear guidelines of what they need to do, including technological guidelines for parents who are not tech savvy. Teachers and parents need to be in constant communication. Setting up a WhatsApp group, or something similar, for parents to be able to support each other and communicate with the teacher can help to ease their anxieties.

Educational institutions should also realise that families may not have multiple devices and that learners may not be able to connect to synchronous learning at specified times. There may be many children at home needing to use a device that is also used by the parent for work. To ease the pressure on parents and learners, asynchronous teaching methods are better so that learning can take place flexibly. Some well-off schools have been replicating the face-to-face time table of classes in an online synchronous manner, requiring learners to sit behind a screen for hours at a time. Long durations behind a screen is not recommended as many learners may lose concentration. Furthermore, it may exclude some learners who don't have the same level of access to devices and the internet. If synchronous online classes are being offered, they should be offered as short sessions and the teachers offering them should be trained in online pedagogies in order to best engage learners. 
To better support parents-turned-teachers, the ministry of education can offer curriculum aligned content in offline ways such as through Kolibri. There are also various openly licensed digital resources to support continued learning through COVID-19.

A last important reminder is for parents to take a break and be kind to themselves as this period can be extremely taxing. These are unusual times and they cannot expect to be both perfect parents and teachers at the same time.

\section{Question 10. Is there an evolving database of e-learning tools that can be used in low-resource settings? If so, is there further information on where these tools are being used and how effective they have been?}

E-learning tools can be unpacked into:

- Virtual Learning Environments;

- Educational software / applications;

- Hardware / devices;

- Educational content / resources.

In conjunction with UNHCR and Learning Equality, the EdTech Hub has created a list of digital resources and tools for primary, secondary and tertiary education.

Offline repositories, Content Management Systems and Virtual Learning Environments such as Kolibri, RACHEL or Rumie offer a low-cost way to deliver curated digital content, without the need for an internet connection. An example of Kolibri in action is the Ugandan government's e-learning portal. Similarly, some Virtual Learning Environments like the Moodle app allow for use offline, and for content and answers to be synced when there is connection. In the case of Virtual Learning Environments, content will need to be curated by educational institutions. There are a variety of open-source Virtual Learning Environments available.

There is also open-source educational software that can be installed on low-cost computers such as Raspberry Pis. The Raspberry Pi Zero is the cheapest model, priced under $\$ 20$. It not only allows learners to access a computer but also introduces them to basic hardware and robotics.

While open-source software on low-cost devices provide a cost-effective solution, it is important to note that these are just the tools, and they will need to be supported by planned lessons and activities to be used effectively. To do this, teachers need first be comfortable with the devices and software, as well as learn how to teach effectively with such tools. Thus, edtech-enhanced teacher professional development is necessary and should precede any implementation of e-learning tools. The success of edtech-enhanced learning depends more on the sustainability of the implementation, the technological and pedagogical readiness of educators and educational institutions, and the digital literacy levels of all parties, than on the e-learning tools. It is thus best to keep the use of e-learning tools light and simple, using as few applications, as little software, and as few platforms as possible. Focus should be placed on supporting gaining proficiency in particular tools and using them effectively.

In terms of examples of what other countries are doing regarding basic education, an array of technologies is being used, including radio, TV, mobile phones and laptops. 
Creating a centralised website or Virtual Learning Environment where curated curriculum content is hosted, has been the main goal. Successful practices included reusing existing content, curating and aligning content to the national curriculum and using multi-modal means to ensure there are many ways to access content (e.g., audio content being on the radio as well as podcast, or videos playing on TV as well being available online).

Question 11. In the TVET sector in Sri Lanka, providing digital skills for trainees who follow non-ICT technical courses will be a big challenge when introducing distance learning. What strategies can be applied to enhance the digital skills of the trainees in non-ICT courses? Furthermore, as many TVET courses require practical training, how can this be shifted to distance learning?

In many TVET courses, large portions of the courses rely on practical and hands-on training. While theoretical and more academic lessons can be done online, it is difficult to do these practical sessions virtually. In this time, distance and online learning can focus on developing learners' soft skills and professional development. For example, online courses could focus on conducting oneself in the workplace, time management, project management, communication skills and negotiation skills. Additionally, there are various online courses (See Class Central, a MOOC aggregator) on improving digital literacy, a skill that is now required in almost all professions. Learners could focus on improving these workplace skills and digital literacy skills while waiting for in-person training to resume.

The Alison platform offers free courses in many technical and vocational topics from skilled trades (e.g., carpentry, masonry, plumbing or motor) to operations (e.g., supply chain management, customer service, or food technology) to health (e.g., nursing, caregiving or pharmacology). This online content could be wrapped and educators could use it to continue teaching remotely.

As some courses absolutely require practical components that cannot be replaced in any way, these lessons will need to be postponed until in-person training can continue. A certain level of in-person, practical training is important and should not be replaced by online learning.

\section{Question 12. Content development is one of the main processes in the distance learning flow. What are the latest convenient tools for content development?}

Before content is developed, Open Educational Resources and MOOCs (which often use openly licensed content) should be searched to ensure that existing content created for the topic does not already exist. If the content does not exist, or needs to be adapted to suit the course aims, then content development can be considered. Within the space, there are instructional design approaches and learning design approaches to content development.

An example of instructional design is the ADDIE framework that has been traditionally used by instructional designers. Figure 1 outlines the five phases ADDIE phases. The 
arrows between each phase indicate that revision, reflection and evaluation should happen between each of the phases.

Figure 1. ADDIE framework

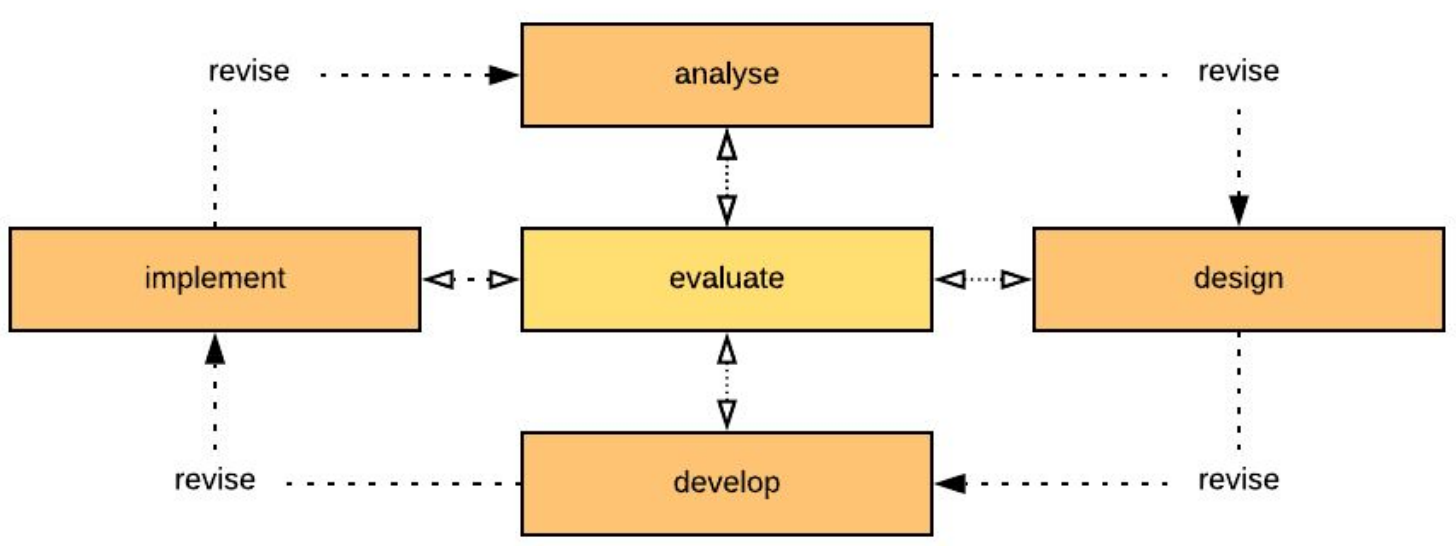

Learning Design is the newer convention that places emphasis on centering the learners as opposed to the instructor. An example of a learning design framework is the Design Thinking for Educators which outlines 5 phases:

1. Discovery. This is where you understand the challenge, prepare research and gather inspiration.

2. Interpretation. This is where you interpret the information gathered, develop user stories, search for meaning and frame opportunities.

3. Ideation. This is where you generate and refine ideas.

4. Experimentation. This is where you make prototypes and gain feedback.

5. Evolution. This is where you track learning and move forward.

Another example of a learning design framework is the 7 C's of Learning Design which outlines 7 stages:

1. Conceptualise. This stage is about creating a vision for the course or module being designed. It helps the teacher / designer think about the nature of the learners who are likely to take the course or module, their age range, diversity, characteristics, skills, perceptions and aspirations.

2. Create. This stage helps the teacher / designer articulate what learning materials need to be created, whether these are text-based,interactive materials, podcasts or videos. In addition, it covers the use or repurposing of Open Educational Resources. The teacher / designer might also create some activities, which require the learners to create their own content.

3. Communicate. This stage is concerned with methods to facilitate communication, between the learner and tutors, the learners and their peers, and the broaders community through social media. This might range from effective mechanisms for fostering discussion in a forum, through effective moderation, or looser communication through social media. 
4. Collaborate. Building upon the communication stage, this stage is about fostering mechanisms to enable collaboration or group work.

5. Consider. This stage is concerned with the ways in which reflection and demonstration of learning achievements can be promoted. Assessments might be diagnostic, formative or summative.

6. Combine. This stage enables the teacher / designer to step back and reflect on the design process to date and look at the design from different perspectives.

7. Consolidate. This stage is about implementing the design in a real-life context and evaluating its effectiveness.

Another popular learning design framework is Universal Design for Learning, which places an emphasis on designing equitably and inclusively, e.g., for learners with disabilities or learners from different cultural backgrounds.

Within all of these design frameworks, the concept of storyboarding is key. Storyboarding is a way of visualising what the content, layout and flow of a course will look like. It is like a lesson plan that includes everything from graphics to video. Storyboards also help to envision learning pathways and branches in the course. They can ensure that various stakeholder views can be included before the content is developed.

\section{Question 13: How effective is use of virtual reality or augmented reality in improving learning outcomes?}

High-tech solutions like virtual reality or augmented reality do not provide value for money, and they have not been shown to improve learning outcomes. Investment is far better spent in solutions such as building offline curated content repositories or educational television shows that can reach more learners, particularly marginalised learners. If the aim of using virtual reality is to create a 'hands-on', practical experience, it is likely that a practical video would be able to achieve a similar impact without the additional costs. 


\section{Appendix A: Materials available from the EdTech Hub}

The following materials developed by the EdTech are available to support governments as they design and implement their response to COVID-19.

1. New analysis by the Hub and our partners to inform your coronavirus (COVID-19) response. https://edtechhub.org/coronavirus/resources-and-tools/

2. Resources from other organisations to support your coronavirus (COVID-19) education response.

https://edtechhub.org/coronavirus/resources-from-other-organisations/

3. Education during the COVID-19 crisis: Opportunities and constraints of using EdTech in low-income countries.

https://edtechhub.org/coronavirus/edtech-low-income-countries/

4. Technical note on the use of virtual learning environments during the COVID-19 pandemic. EdTech Hub.

http://docs.edtechhub.org/lib/?page=2\&page-len=1\&sort=date desc

5. The role of interactive radio instruction in the coronavirus (COVID-19) education response.

https://edtechhub.org/2020/04/23/the-role-of-interactive-radio-instruction-in-the -coronavirus-covid-19-education-response/

6. Continue or reboot? Overarching options for education responses to coronavirus (COVID-19) in low- and middle-income countries. EdTechHub.

https://edtechhub.org/2020/04/17/continue-or-reboot-overarching-options-for-e ducation-responses-to-coronavirus-covid-19-in-low-and-middle-income-countries $\underline{1}$

7. Zero-rating educational content in low- and middle-income countries. EdTechHub. http://docs.edtechhub.org/lib/?page=1\&page-len=1\&sort=date desc

8. A five-part education response to the COVID-19 pandemic. EdTechHub. http://docs.edtechhub.org/lib/JLEWADHF

9. Nepal "Ask me anything" Session: Responses to audience questions. EdTechHub. http://docs.edtechhub.org/lib/UXQG7GRG

10. Back-to-School Campaigns Following Disruptions to Education. EdTechHub. http://docs.edtechhub.org/lib/DS66UGW4

As more documents are released, they will be continuously updated on The EdTech Hub document library. 
Appendix B: Open Educational Resources Repositories for Higher Education

\begin{tabular}{|c|c|}
\hline Resource & Link \\
\hline Andy Schmitz 2012 Book Archive & $\begin{array}{l}\text { https://web.archive.org/web/20151129064646/h } \\
\text { ttps://2012books.lardbucket.org/ }\end{array}$ \\
\hline $\begin{array}{l}\text { Community College Consortium } \\
\text { for OER }\end{array}$ & https://www.cccoer.org/learn/find-oer/ \\
\hline Digital Learning Resources List & $\begin{array}{l}\text { https://www.unhcr.org/education/Digital-Learni } \\
\underline{\text { ng-Resources-List.xlsx }}\end{array}$ \\
\hline $\begin{array}{l}\text { International Partnership of } \\
\text { Distance and Online Learning for } \\
\text { COVID-19 }\end{array}$ & https://opendoor.col.org/ \\
\hline $\begin{array}{l}\text { IRSC Libraries General OER } \\
\text { Repositories }\end{array}$ & $\begin{array}{l}\text { https://irsc.libguides.com/openeducationalresou } \\
\underline{\text { rces/oerrepositories }}\end{array}$ \\
\hline MIT OpenCourseware & https://ocw.mit.edu/index.htm \\
\hline OER Africa & https://www.oerafrica.org/ \\
\hline OER Commons & https://www.oercommons.org/ \\
\hline OERu & https://oeru.org/ \\
\hline $\begin{array}{l}\text { Remote learning, distance } \\
\text { education and online learning } \\
\text { during the COVID19 pandemic: A } \\
\text { Resource List by the World Bank's } \\
\text { EdTech Team }\end{array}$ & $\begin{array}{l}\text { http://documents.worldbank.org/curated/en/96 } \\
\text { 4121585254860581/pdf/Remote-Learning-Dista } \\
\text { nce-Education-and-Online-Learning-During-the- } \\
\text { COVID19-Pandemic-A-Resource-List-by-the-Worl } \\
\text { d-Banks-Edtech-Team.pdf }\end{array}$ \\
\hline $\begin{array}{l}\text { Solvonauts Open Educational } \\
\text { Resource Repository }\end{array}$ & http://solvonauts.org/ \\
\hline $\begin{array}{l}\text { Teacher Education in Sub-Saharan } \\
\text { Africa }\end{array}$ & http://www.tessafrica.net/ \\
\hline
\end{tabular}




\begin{tabular}{|l|l|}
\hline The Mason OER Metafinder & $\begin{array}{l}\underline{\text { https://mason.deepwebaccess.com/mason Ma }} \\
\text { sonLibrariesOpenEducationResources 5f4/deskt } \\
\text { op/en/search.html }\end{array}$ \\
\hline $\begin{array}{l}\text { UNHCR- List of digital learning } \\
\text { resources with open licensing }\end{array}$ & $\begin{array}{l}\underline{\text { https://www.unhcr.org/education/Digital-Learni }} \\
\underline{\text { ng-Resources-List.xlsx }}\end{array}$ \\
\hline $\begin{array}{l}\text { University of Massachusetts OER } \\
\text { Repositories }\end{array}$ & $\underline{\underline{\text { https://www.library.umass.edu/oer/oer-reposito }}}$ \\
\hline $\begin{array}{l}\text { University of Pittsburgh Open } \\
\text { Educational Resources: Big List of } \\
\text { Resources }\end{array}$ & $\underline{\text { https://pitt.libguides.com/openeducation/biglist }}$ \\
\hline $\begin{array}{l}\text { University of Witwatersrand OER } \\
\text { Resources }\end{array}$ & $\underline{\text { https://libguides.wits.ac.za/c.php?g=145371\&p= }}$ \\
\hline
\end{tabular}




\section{References}

Adam, T. (2020). Between Social Justice and Decolonisation: Exploring South African MOOC Designers' Conceptualisations and Approaches to Addressing Injustices. Journal of Interactive Media in Education, 2020(1), 7. https://doi.org/10.5334/jime.557

Bozkurt, A. (2019). From Distance Education to Open and Distance Learning: A Holistic Evaluation of History, Definitions, and Theories. Handbook of Research on Learning in the Age of Transhumanism.

\section{https://doi.org/10.4018/978-1-5225-8431-5.ch016}

Bozkurt, A., Jung, I., Xiao, J., Vladimirschi, V., Schuwer, R., Egorov, G., Lambert, S., Al-Freih, M., Pete, J., Don Olcott, J., Rodes, V., Aranciaga, I., Bali, M., Alvarez, A. J., Roberts, J., Pazurek, A., Raffaghelli, J. E., Panagiotou, N., Coëtlogon, P. de, ... Paskevicius, M. (2020). A global outlook to the interruption of education due to COVID-19 pandemic: Navigating in a time of uncertainty and crisis. Asian Journal of Distance Education, 15(1), 1-126.

Deacon, A., Jaffer, T., Jawitz, J., Small, J., \& Walji, S. (2018). Wrapping of a Social Innovation MOOC. ICEL 2018 13th International Conference on E-Learning, 61.

Kelly, N., \& Antonio, A. (2016). Teacher peer support in social network sites. Teaching and Teacher Education, 56, 138-149. https://doi.org/10.1016/j.tate.2016.02.007 Plan International. (2016). Education Needs Assessment Report-Sierra Leone. USAID. (2020). Delivering Distance Education in Emergencies: A Review of Evidence and Best Practice. USAID. 